Article

\title{
Seismic Retrofit Measures for Masonry Walls of Historical Buildings, from an Energy Saving Perspective
}

\author{
Mariangela De Vita *, Antonio Mannella ${ }^{(\mathbb{D}}$, Antonio Sabino and Alessio Marchetti \\ Construction Technologies Institute CNR, Via G. Carducci 32 C, 67100 L'Aquila, Italy; \\ antonio.mannella@itc.cnr.it (A.M.); antonio.sabino@itc.cnr.it (A.S.); alessio.marchetti@itc.cnr.it (A.M.) \\ * Correspondence: ing.mariangeladevita@gmail.com; Tel.: +39-329-1750844
}

Received: 25 January 2018; Accepted: 23 March 2018; Published: 27 March 2018

\begin{abstract}
The planning of energy saving and structural retrofit interventions on masonry buildings are usually two separate projects; combined interventions are rare. Solutions tackling both aspects can reduce total refurbishment costs and improve global building performance. However, heavy interventions on the envelope have to be carefully designed in order to improve both seismic and energy performance whilst mitigating environmental impact. National energy saving regulations are generally less strict for historical buildings, making this category of buildings very interesting not only because of their widespread diffusion across Italy but also because of the possibility of planning interventions that will allow significant improvements by combining building efficiency and safety. This research looks at these aspects and proposes new methods for refurbishing masonry buildings combining seismic improvements and energy saving interventions. Among those mostly commonly applied on masonry buildings in Italy, and described in this paper, are various combined retrofit interventions, and we report the results of these interventions on thermal transmittance reduction and global costs.
\end{abstract}

Keywords: historical building; seismic and energy retrofit; combined interventions; U-value; historical masonry

\section{Introduction}

This article analyses the results of a wide-ranging study investigating the effects on energy performance of masonry buildings with historical/heritage value that have undergone typical seismic improvement interventions. The most frequently used techniques have been examined by analyzing, for each of them, the resulting effect on energy performances of the envelope in order to evaluate the variation of thermal properties of the materials employed for structures and finishes.

A significant part of Europe's building heritage is made up of old buildings [1-4] constructed using poor quality insulation materials. Therefore, recent regulations, such as the EU Directive 2010/31 [5] on buildings' energy efficiency, aim to increase energy efficiency standards, by considering both the single components and the entire building. In Italy, the energy improvement intervention regulated by the Legislative Decree [6] takes into account the European Directive 2002/91/CE [7]; actual regulations have been updated several times to comply with new European directives. The current energy saving standards have been recently integrated with a set of NZEB objective norms; last updates of 90/2013 law have been published in the Official Journal of the Italian Republic, 15 July 2015, n.39 [8]. However, the application of the aforementioned legislation is subordinate to Italy's own cultural conservation principles. Rules concerning the Italian energy performance certificate (APE), to check thermal installations, are still valid, whilst any other intervention must be evaluated by the local office 
of Ministry of Cultural Heritage and Activities and Tourism (MiBACT). The latter office evaluates, case by case, the adequacy of interventions. Despite their best intentions [5,8], current regulations have led to an increase in the gap in required performance between new buildings and historical buildings. Furthermore, a substantial absence of general rules about better compatibility among available energy retrofit technologies and other eligible interventions can lead to differences in treatment of similar cases in several contexts [9].

In recent years, a number of investigations have looked at energy saving and structural aspects. Different approaches have been adopted, ranging from holistic ones [10], dynamic simulations of entire buildings [11], to specific solutions such as the adoption of a thermal, vegetal based, insulating plaster [12].

An interesting multidisciplinary approach was investigated by Ascione et al., Mannella et al. and De Berardinis et al. [13-15]: they proposed a replicable methodology for improving the performance of historic buildings based on preliminary historical analysis, structural diagnosis and in-situ investigations. This multidisciplinary approach to building structural and energy diagnoses was applied to a case study obtaining a model to predict the structural safety of the building and its energy consumption. Tiberi and Carbonara [16] explored aspects relating to retrofitting interventions for energy saving and the financial costs, introducing a case study and finding four solutions for the envelope; Calvi et al. [17] presented an integrated approach to seismic resilience and energy efficiency assessments. Marques et al. and Calvi $[18,19]$ performed an in-depth cost-benefit analysis of the strengthening solutions, comparing the economic benefit gained by reducing the seismic damage against the intervention cost. More recently, smart and innovative integrated systems have also been designed in order to achieve important energy and environmental benefits regarding historical buildings [20,21].

The state of the art approach leans towards combined interventions and multidisciplinary approaches in the refurbishment process; however, it is important to understand the interactions going on. This study highlights how the execution of some of the most adopted typologies of structural improvement intervention on the outer walls typically cause an increase of the envelope thermal transmittance and, consequently, a general worsening of the energy performance of the building. However, an appropriate selection of materials and the techniques employed, with a very small increase in working times and costs, allows a rebalancing and even, in some cases, a notable reduction in thermal conductivity whilst respecting the original historical values of the buildings. The analyses carried out permit us to evaluate the impact of current regulation on energy efficiency in buildings that constitute Italy's cultural heritage [22].

\section{Materials and Methods}

The impact on buildings' energy efficiency produced by structural improvement interventions is analyzed below focusing on conductivity and thermal transmittance of the envelope. This work analyzes some of the most common structural improvement interventions on various kinds of masonry and typically occurring in the historical buildings of central Italy (a territory characterized by important seismic events and by historical buildings, as shown in Figure 1).

The investigated interventions are often used for the seismic retrofit of buildings damaged by earthquakes [23]. In general, restoration projects that include seismic improvements use several different types of intervention. Figure 2 illustrates the distribution of the principal interventions carried out on masonry buildings located outside the historical center of L'Aquila after the earthquake $(\mathrm{Mw}=6.3)$ that occurred in the Abruzzi region on the 6 April $2009[24,25]$. Figure 2a shows the distribution of the most diffuse interventions and Figure $2 b$ shows the distribution of secondary interventions: main intervention, for each building, refers to more widespread and costly work typology; secondary interventions, on the other hand, are complementary to the main ones. 


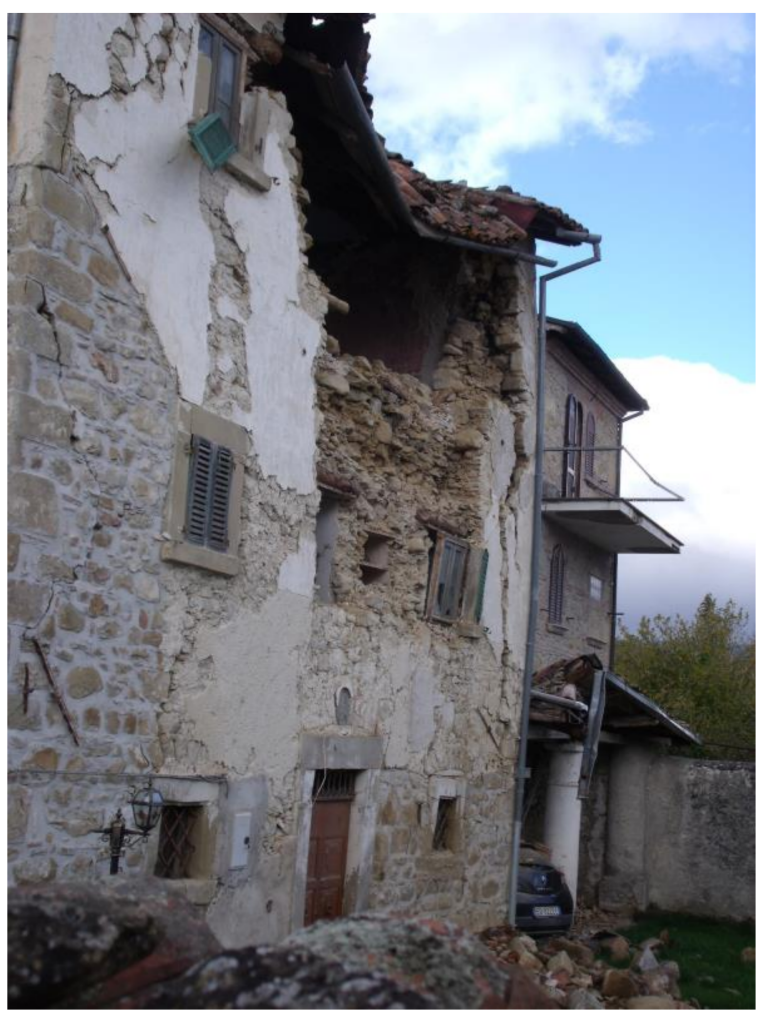

(a)

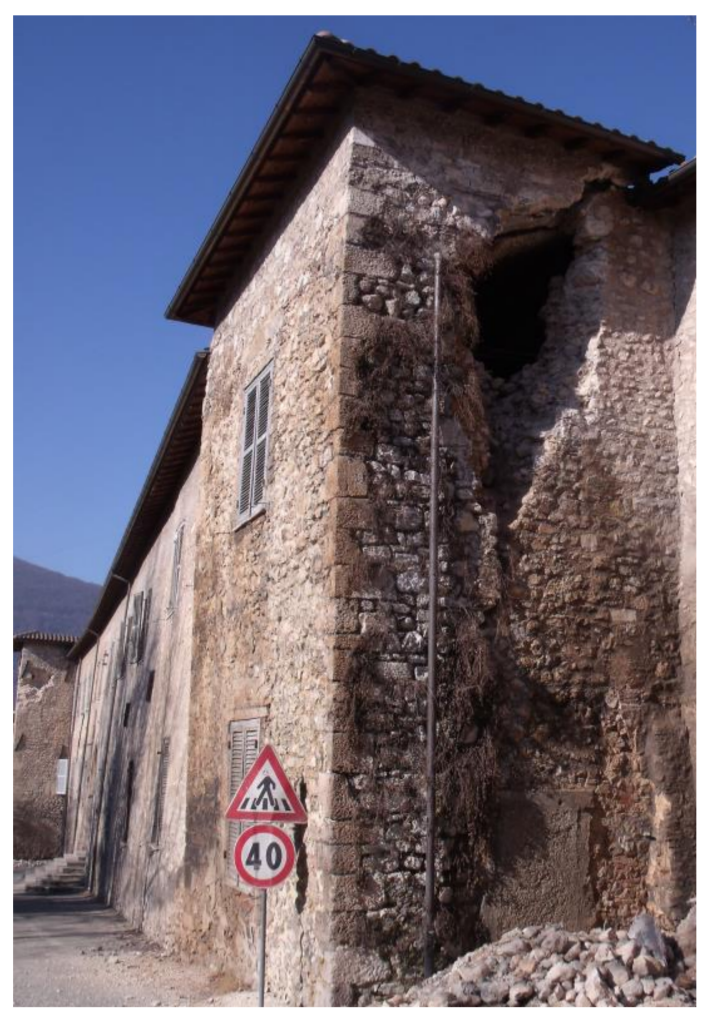

(b)

Figure 1. Historical buildings heavily damaged by the earthquake that occurred on 30 October 2016 in Central Italy: (a) Exterior view of the residential building; (b) Fortified residence.

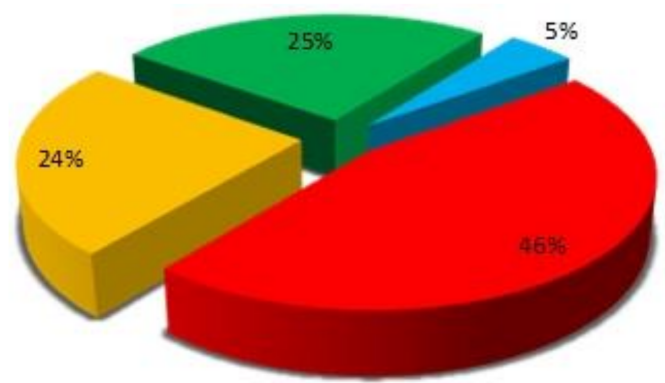

(a)

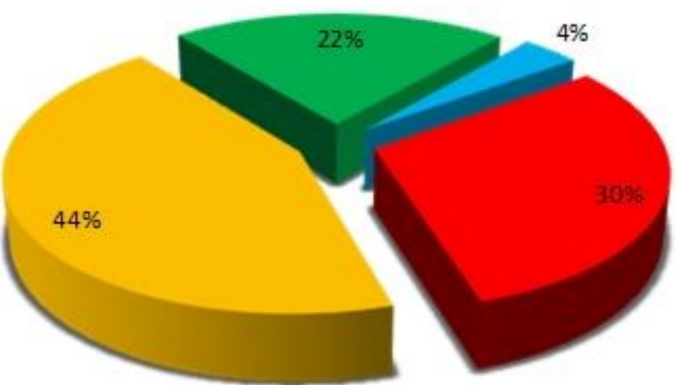

(b)

Figure 2. Type and frequency of techniques for (a) main and (b) secondary interventions to historical buildings after the Abruzzo earthquake of 6 April 2009 in Abruzzo. Red: strengthening of masonry walls (i.e., reinforced plastering mortar, injections, diàtonoi); yellow: single, individual interventions; green: application of tie-rods in connections and walls; blue: interventions related to the foundations.

\subsection{Methodology}

The methodology for this research involves seven steps and terminates with an optimization of the interventions carried out. The methodology of the study is the following:

- $\quad$ Step 1: execution of preliminary investigations on the morphology of the masonry and evaluation of the thermal physical state of the envelope;

- Step 2: application of the most common interventions for the structural improvement of the investigated masonries; 
- Step 3: application of the most common energy efficiency interventions, compatible with the structural interventions chosen in the previous step;

- $\quad$ Step 4: determination of the new thermal-physical characteristics of the masonries using thermal equivalent conductivity ( $\lambda \mathrm{eq})$;

- $\quad$ Step 5: comparison between the thermal transmittance (U-value) of the masonries after seismic retrofitting intervention and after energy retrofitting interventions combined with seismic retrofitting interventions;

- Step 6: economic analyses of each of the solutions analyzed, to show the advantages and disadvantages of using combined solutions;

- $\quad$ Step 7: evaluation of the design process to optimize the balance between cost and work, to achieve structural improvement as well as adequate energy saving.

\subsection{Masonry Types and Thermal Properties}

This research relates to the variations of the thermal properties of each material making up the walls after seismic retrofitting interventions: the analyses carried out aim to establish the new values of the U-value of the masonry.

In the case of heterogeneous materials, like masonry, it is not formally correct to use thermal conductivity because the flux is not solely due to conduction but also to convection and radiation in the internal cavities of the wall. For this reason, the study was conducted by varying the thickness of each layer of masonry analyzed (masonry cut stones with possible rubble in-fill). Table 1 shows the values of $\lambda$ eq for different value of thicknesses.

Table 1. Main properties of investigated masonries. The thickness values refer only to the thickness of the masonry, not the total wall section.

\begin{tabular}{ccc}
\hline Material & $\rho\left(\mathbf{k g} / \mathbf{m}^{\mathbf{3}}\right)$ & $\lambda \mathbf{e q}(\mathbf{W} / \mathbf{m K})$ \\
\hline Masonry 20 cm thickness & 2100 & 2.4 \\
Masonry 26 cm thickness & 2100 & 2.28 \\
Masonry 36 cm thickness & 2100 & 2.14 \\
Masonry 56 cm thickness & 2100 & 2.02 \\
Masonry 76 cm thickness & 2100 & 1.94 \\
Rubble & 1500 & 0.7 \\
\hline
\end{tabular}

To calculate the U-value of heterogeneous structures, reference was made to the UNI EN ISO 6946:2008 and EN ISO 12567-1 [26,27], that also specify a method to measure the thermal conductivity of homogeneous materials. For the reference values of thermal conductivity for common building materials, references used are in the following standards: UNI 10351:2015 (homogeneous materials) and UNI 10355:1994 (not homogeneous materials) [28,29].

The next step was to define the whole section of the wall using the equivalent conductivity of the masonries described in Table 1. Thus, it was possible to determine, in six typical configurations investigated, the impact of the most common structural improvement interventions on the masonry thermal properties. The most recurrent envelope thicknesses in the Italian historical buildings of the Central Apennines were considered. Table 2 shows the outer walls investigated in some selected different thicknesses. In the table below, the middle column refers to the wall section layout characterized in terms of the constituting layers: e.g., section "plaster (2) masonry (20) rubble (8) masonry (20) plaster (2)" refers to a section with five layers, namely a 2-leaf wall with main layers made of stone masonry, with $20 \mathrm{~cm}$ thickness for each one, a filling layer of rubble stone with $8 \mathrm{~cm}$ thickness, and the plaster on both faces with an average thickness of $2 \mathrm{~cm}$.

The execution of seismic retrofitting interventions generally involves the removal and then remaking of one or both of the external finishing plasters. In this case, the new plasters are made with high mechanical performance pre-mixed materials based on pozzolanic binders or mixed lime/cement. 
Then a final finishing layer, made of lime-based plaster for the interior surface of the wall and cement-based plaster for exteriors, is spread on the masonry surface. In Table 3, various types of most common used plasters are shown, including some high thermal performance plasters.

Table 2. Wall thickness composition (in $\mathrm{cm}$ ) and the U-value for all the samples analyzed. The finishes are lime/gypsum plasters.

\begin{tabular}{ccc}
\hline ID & Wall Section Layout (cm) & $\mathbf{U}\left(\mathbf{W} / \mathbf{m}^{\mathbf{2}} \mathbf{K}\right)$ \\
\hline MS4 & plaster (2) masonry (36) plaster (2) & 2.485 \\
MS6 & plaster (2) masonry (56) plaster (2) & 1.955 \\
MS8 & plaster (2) masonry (76) plaster (2) & 1.598 \\
MR4 & plaster (2) masonry (20) rubble (8) masonry (20) plaster (2) & 1.941 \\
MR6 & plaster (2) masonry (26) rubble (8) masonry (26) plaster (2) & 1.734 \\
MR8 & plaster (2) masonry (26) rubble (24) masonry (26) plaster (2) & 1.242 \\
\hline
\end{tabular}

Table 3. Water vapor resistance coefficient $\mu$ and conductivity $\lambda$ of finishes.

\begin{tabular}{ccc}
\hline Material & $\mu$ & $\lambda(\mathbf{W} / \mathbf{m K})$ \\
\hline Lime/gypsum plaster, interior side & 10.7 & 0.7 \\
Plaster $(c=1000 \mathrm{~J} / \mathrm{kgK})$, exterior side & 22.7 & 0.9 \\
Plaster $(c=$ 840 J/kgK), exterior side & 22.7 & 0.9 \\
Lime or lime/cement mortar & 22.7 & 0.9 \\
Thermal insulating plaster 1 1 & $<9$ & 0.09 \\
Thermal insulating plaster 2 $^{1}$ & 4.5 & 0.075 \\
Thermal insulating plaster 3 $^{1}$ & 4 & 0.045 \\
\hline
\end{tabular}

${ }^{1}$ The thermal characteristics of the insulating plasters derive from the average of the values declared in technical sheets of the most used commercial products.

Often the plasters in Table 3 replace the historic lime finishes, generating a further change of the envelope thermal performance; for this reason, the choice of finishes with specific characteristics is very important in the refurbishment process. Planners must pay close attention to the choice of materials and their combination in the design phase of the retrofit intervention because this strongly determines the performance of the enclosure. Different combinations of the materials described above will be shown in the next sections in order to define the most frequent types of structural intervention on the masonry and their new thermal characteristics.

\section{Case Study}

The structural retrofit of historical buildings has achieved commendable results in the last few decades from both a regulatory and an applicative point of view [30] and is the result of research as well as historical and technical traditions, which have been fully adopted by practitioners and designers. Research suggests that when planning structural interventions, the one solution fits all approach is not effective and each intervention must be assessed with a case by case approach.

This methodology is the result of an interdisciplinary dialogue that has been taking place for some time among engineers, restorers and technicians. This interdisciplinary dialogue has not, unfortunately, been extended to the energy installations sector, which still today proceeds in a somewhat ad hoc style notwithstanding recent significant developments in this field. Indeed, an absence of specific studies on the relationship between restoration, structures and installations often results in a design that is aware of neither its own limits nor its potential.

\subsection{Seismic Retrofit on Vertical Structures}

The study focuses on the analysis of stone masonry that characterizes the building technology most often found in historical and valuable buildings. Although a variety of materials and techniques are 
used, masonry presents recurrent problems with regards to seismic vulnerability and the applicability of the reinforcement techniques most frequently used. Generally the vertical structures examined are constituted by irregular shaped, stone elements (unworked stone, often of irregular shape, of different dimensions and sometimes even of different materials) that have been used to build one or more leafs. The connections between single stone blocks constituting the wall are made with low quality mortar in terms of their composition and strength. For this type of masonry, often poorly connected to the horizontal structures, the effects of seismic forces may create conditions of instability. These are related to the disintegration of the wall or part of it (expulsion of the outer leaf), to activation of kinematic mechanisms (out-of-plane or other mechanisms of local collapse) or to second mode damage due to forces acting in the plane of the wall (in-plane shear or buckling).

Interventions on masonry vertical structures are designed to increase the mechanical strength and ductility of the walls, improving the behaviour of the building subjected to static and seismic loads. The materials used are selected so as to obtain the chemical-physical and mechanical characteristics as compatible as possible with the original materials. Technical standards, mostly normalized in EU, give specific instructions about the mechanical qualification and the durability of the materials treated, which can be used for structural applications only if CE marked. Specific procedures are also defined for the classification of materials with specific characteristics of thermal conductivity, employable in the context of energy efficiency interventions. However, commercial products for which the thermal characteristics are specified and also appropriate for structural purpose are very few, and in particular, until now, no grout or structural plaster fall into this category.

The most common structural interventions can be classified into three main categories: localized repairs; localized improvement interventions that interest single discontinuity of the wall structure (such as filling of the cavities); and general improvement of the masonry characteristics, with specific actions taken to mitigate vulnerabilities associated with the type of brickwork and/or its structural elements and mortar. These interventions range from local rebuilding methodology: scuci-cuci (substitution of damaged elements with new ones, reestablishment of the structural continuity), that aims to restore the wall continuity along cracking lines; to mortar bed-joint repointing that improves deteriorated joints (both reinforced or not); to insertion of artificial diàtonoi (= stones which run through the thickness of the wall and bind it together as described by Vitruvius in [30]), that consists in the improvement of the connection between multi-leaf masonry walls via the insertion of small tie beams across the wall in a regular pattern; and to external reinforcement (jacketing with Fiber Reinforced Polymers, Glass Fiber Reinforced Polymers or grids of steel) [31,32].

Particular attention is given to the consequences that interventions of mortar injections (Figure 3) facing of masonries with reinforced plaster and the insertion of artificial diàtonoi have on the thermophysical characteristics of the wall surface. The decision to focus on these kinds of intervention was because of their frequent use and massive and diffuse application. 


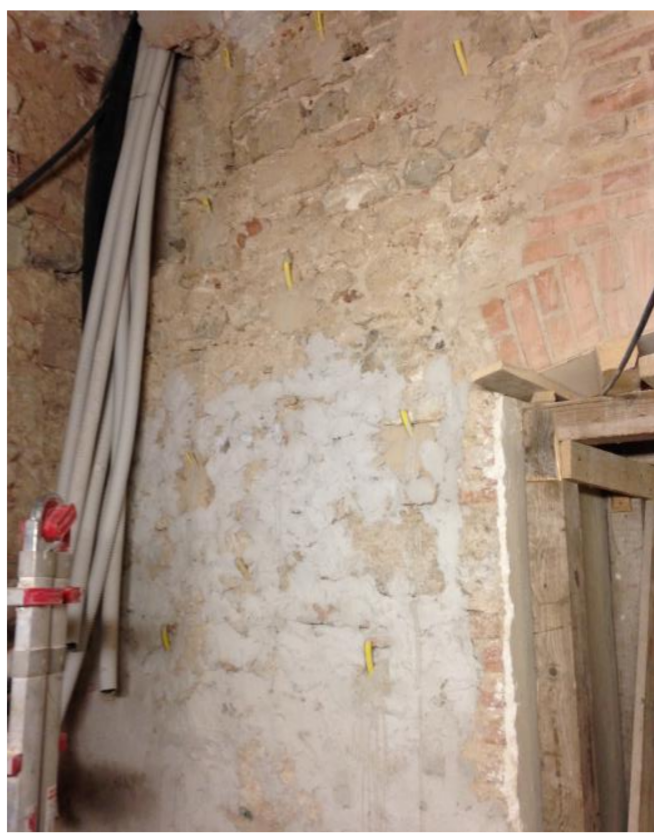

(a)
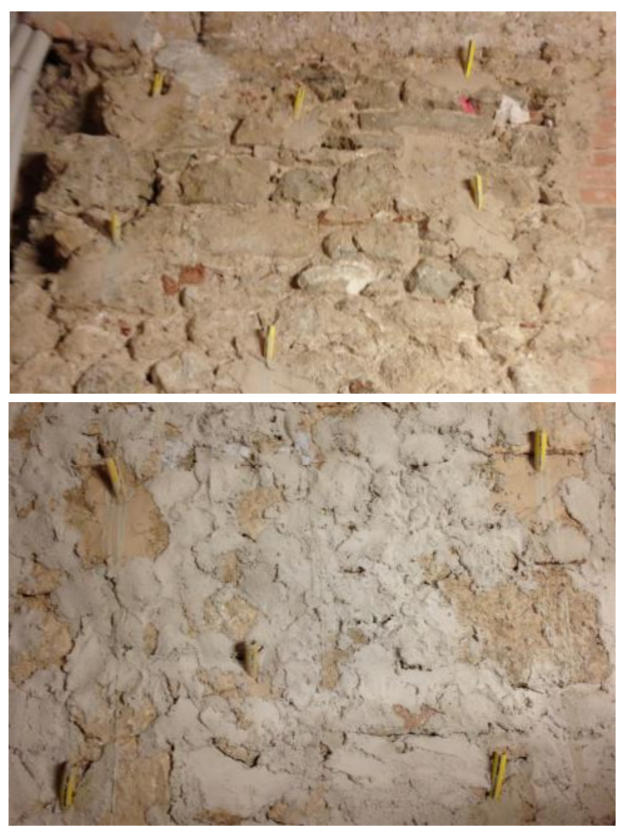

(b)

Figure 3. Example of grout injected masonry in an historical building in L'Aquila: (a) cannulae distribution on the wall; (b) details.

\subsection{Energy Efficiency Interventions on Outer Walls in Historical Buildings}

Preliminary evaluations of interventions for structural improvement allow us to define appropriate combined solutions for the energy efficiency of the building. In fact, the possibility of adopting solutions that are more or less invasive will depend on the degree of invasiveness of the structural intervention. Insulating materials can be used both inside and outside buildings, and external insulation, if carried out without interruption on the surface and with suitable materials, is capable of creating a continuous barrier to the heat transfer and hence controlling humidity on the internal side of the wall. It follows that where possible, the application of an external insulation is preferable to an internal insulation [22].

In the Table 4, all the retrofit interventions analyzed (either seismic and/or combined with energetic interventions) are described. The last intervention shows the characteristics of exterior insulation finishing system (EIFS) used in energy efficiency interventions. By way of comparison, Table 9 illustrates the results of applying EIFS in three different thicknesses: $3 \mathrm{~cm}, 6 \mathrm{~cm}$ and $10 \mathrm{~cm}$.

Table 4. Definition of the seismic and energetic interventions.

\begin{tabular}{cc}
\hline ID & Interventions \\
\hline GI1 & Grout injections and $2 \mathrm{~cm}$ of finishing cement plaster $(\lambda=1)$ \\
GI + RP & Grout injections + reinforced plaster and $3 \mathrm{~cm}$ of finishing cement plaster $(\lambda=1)$ \\
RP & Reinforced plaster and $3 \mathrm{~cm}$ of finishing cement plaster $(\lambda=1)$ \\
D32 & Artificial diàtonoi of $32 \mathrm{~mm}$ diameter and original finishing plaster \\
D100 & Artificial diàtonoi of $100 \mathrm{~mm}$ diameter and original finishing plaster \\
TP1 & $3 \mathrm{~cm}$ of thermal insulating plaster $(\lambda=0.075)$, exterior side \\
TP2 & $3 \mathrm{~cm}$ of thermal insulating plaster $(\lambda=0.075)$, exterior and interior side \\
EIFS & Ext. Insulation Finishing System $(\lambda=0.04)$ and $1 \mathrm{~cm}$ of finishing plaster $(\lambda=0.7)$ \\
\hline
\end{tabular}

\section{Non-Destructive Testing}

The thermal characteristics of stone walls are directly related to the amount of voids in the masonry. This parameter is also related to the resistance of the masonry, in terms of bearing and shear 
strength. The amount of voids inside the masonry also affects its thermal characteristics, especially with an increasing regularity of the stone elements; thus with a minor percentage of voids, it is possible to observe an increase of the equivalent conductivity. Given the lack of specific experimental results, non-destructive testing was used to obtain velocity measurements and injectability measurements of different sample walls in order to estimate the voids' percentage and consequently the thermal characteristics variations of the masonry walls as a result of grout interventions.

\subsection{Sonic Tests to Evaluate the Percentage of Cavities in Rubble Masonries}

The sonic test is a non-destructive test that measures the speed of propagation of elastic waves within a wall. These waves are produced by a pulse generator (usually an instrumented hammer) and recorded by a receiver. The wave velocity increases with the bulk density of material. Thus, the tests are able to provide indications of a qualitative nature on the strength of the masonry and the presence of cavities, cracks or material heterogeneity intercepted along the wave path. For research purposes, knowing the percentage of injected voids is fundamental to estimate the physical properties of the wall, such as thermal insulation and breathability.

Results of the experimental testing by Artioli et al. [33] carried out on rubble masonry walls of historic buildings affected by the 2009 L'Aquila earthquake, in Italy, were used for the characterization of rubble masonry. That study has identified six severely damaged buildings in the urban centers of Onna, Tempera and Sant'Eusanio Forconese, in the Aterno Valley (L'Aquila, Italy). From these buildings 21 masonry portions were obtained and investigated with sonic tests before and after the injection of grout. These walls are representative of the rubble masonry widespread in Central Italy. The rubble between the two faces is of limited size, and consists of small pieces of stone mixed with the same mortar used for laying the stones.

During the interventions, the injection time of each single hole was monitored to estimate approximately the amount of grout injected and the percentages of injected cavities. Through sonic tests, a map of sonic speeds, made up of a square grid of measuring points with distances $0.20 \mathrm{~m} \times 0.20 \mathrm{~m}$, was obtained.

The research [33] shows that although the percentage of injected voids is placed between $7 \%$ and $18 \%$, and on average $12 \%$, the increases in terms of sonic speeds reach values of approximately $2000 \mathrm{~m} / \mathrm{s}$, corresponding to $380 \%$ of the original speeds. This result could depend on the sonic wave path that decreases substantially after the injections because the waves do not intercept cavities and the wave is propagated through the densest part of the masonry, regardless of the percentage of the injected voids. Seeing as it is possible to assimilate the propagation of the heat flow through the wall to the sonic wave, it is also right to suppose a very high increase of the conductivity values in the post-intervention. However, in this study the increase of the equivalent thermal conductivity of the injected rubble masonry has been determined by assigning to it the same value of the average amount of percentage of injected voids, equal to $12 \%$.

\subsection{Grout Injection Tests to Evaluate the Percentage of Voids on Irregular Stone Masonry}

For the characterization of irregular shape, stone masonry, reference was made to the values provided by a grout injection test performed during the post-earthquake reconstruction in L'Aquila, in two buildings located in Via S. Marciano and in Via dei Vetusti (Tables 5 and 6). The injected masonry has a $60 \mathrm{~cm}$ thickness and is made of hewn stone in a single wall. The injection was performed by the execution of $1.4 \mathrm{~cm}$ diameter holes. The holes length was approximately $2 / 3$ of the wall thickness and $1.2 \mathrm{~cm}$ diameter cannulae with $1 \mathrm{~cm}$ diameter internal hole were used (the cannula was inserted approximately $30 \mathrm{~cm}$ into the interior of the wall and sealed with mortar). The injections were planted $50 \mathrm{~cm} \times 50 \mathrm{~cm}$ in the traditional staggered pattern. The testing allowed us to estimate that internal cavities were around three percent of the gross volume of the masonry; therefore, for this masonry typology the same value was assumed for the equivalent thermal conductivity increase. 
Table 5. Sample $1(3.20 \mathrm{~m} \times 1.5 \mathrm{~m})$, from a masonry wall reinforced with injections in the post-earthquake reconstruction. The building is located in Via S. Marciano, L'Aquila, Italy.

\begin{tabular}{cc}
\hline Sample 1, Via San Marciano & Survey Results \\
\hline total area covered & $4.8 \mathrm{~m}^{2}$ \\
number of holes & 19 \\
total injected material & $150 \mathrm{~kg}$ \\
average material injected per unit area & $30 \mathrm{~kg} / \mathrm{m}^{2}\left(\right.$ approximately $60 \mathrm{~kg} / \mathrm{m}^{3}$ wall) \\
number of holes not responsive & 5 \\
number of little responsive holes & 7 \\
number of very responsive holes & 7 \\
\hline
\end{tabular}

Table 6. Sample $2(1.9 \mathrm{~m} \times 1.6 \mathrm{~m})$, from a masonry wall reinforced with injections in the post-earthquake reconstruction. The building is located in Via Vetusti, L'Aquila, Italy.

\begin{tabular}{cc}
\hline Sample 2, Via Vetusti & Survey Results \\
\hline total area covered & $3 \mathrm{~m}^{2}$ \\
number of holes & 14 \\
total injected material & $87.5 \mathrm{~kg}$ \\
average material injected per unit area & $28 \mathrm{~kg} / \mathrm{m}^{2}$ (approximately $58 \mathrm{~kg} / \mathrm{m}^{3}$ wall) \\
number of holes not responsive & 4 \\
number of little responsive holes & 7 \\
number of very responsive holes & 3 \\
\hline
\end{tabular}

\section{Results}

The analyses on the walls were carried out by calculating the variation of the equivalent conductivity as a result of three main interventions: grout injections, grout injections and plaster reinforced with welded wire mesh, and insertion of artificial cement diàtonoi with a thickness of $32 \mathrm{~mm}$ and $100 \mathrm{~mm}$. The new equivalent conductivity obtained from the analyses is related to the several masonry types investigated and is shown in Table 7. The subscripts refers to the intervention IDs defined in Table 4. All values have been obtained without considering the finishing.

Table 7. Values of $\lambda$ eq $(\mathrm{W} / \mathrm{mK})$ after different kind of interventions.

\begin{tabular}{ccccccc}
\hline Masonry & $\lambda_{\text {eq }}$ & $\lambda_{\text {GI1 }}$ & $\lambda_{\text {RP }}$ & $\lambda_{\text {GI }+ \text { RP }}$ & $\lambda_{\text {D32 }}$ & $\lambda_{\text {D100 }}$ \\
\hline MS4 & 2.14 & 2.20 & 2.145 & 2.204 & 2.16 & 2.149 \\
MS6 & 2.02 & 2.08 & 2.025 & 2.085 & 2.04 & 2.025 \\
MS8 & 1.94 & 1.99 & 1.96 & 2.002 & 1.97 & 1.95 \\
MR4 & 1.71 & 1.91 & 1.724 & 1.914 & 1.75 & 1.75 \\
MR6 & 1.75 & 1.96 & 1.764 & 1.974 & 1.79 & 1.79 \\
MR8 & 1.331 & 1.49 & 1.34 & 1.502 & 1.37 & 1.38 \\
\hline
\end{tabular}

The first case (GI1) is related to a retrofit intervention with grout injections: the new conductivity value was calculated according to the results provided by the experimental tests and in particular for the rubble masonry, reference was made to the non-destructive sonic tests $(12 \%$ of the masonry volume is empty before the intervention and filled with grout after the intervention). For the irregular stone masonry, reference was made to the grout injection testing (three percent of the masonry volume is filled of air before the intervention and filled with grout after the intervention). The second case (RP) regards the strengthening of masonry with reinforced plaster. The third type of consolidation investigated $(\mathrm{GI}+\mathrm{RP})$ concerns combined interventions of grout injections and reinforced plaster: in this case the value of the post-intervention conductivity is higher than the two previous cases, because of both the injection and the steel roads inserted into the masonry. The latest investigated configurations are related to diàtonos interventions (D32 and D100): because of the lower invasiveness 
of the intervention the conductivity increase is small. For the cases D32 and D100, four diàtonoi per unit area were considered and, in the analyses of the thermal properties of the reinforced surface, the U-value was computed in parallel. Each diàtonos was armed with a $\phi 16$ bar. The conductivity of the reinforced masonry through RP was obtained considering the presence of five $\phi 8$ parallel bars per unit area of wall. The results of the analyses carried out in order to obtain the new masonry U-values corresponding to GI1, RP and GI + RP interventions and related to the whole section of wall, are shown in the table below.

Despite the seismic intervention analyzed in Table 8, diàtonos interventions do not modify the U-value significantly (see Figure 4); for this reason, in the next steps of the analyses carried out, no energy efficiency interventions were applied.

Once the equivalent conductivity of the structural part of the masonry was calculated (Table 7), the possibility of producing variations in the U-value relating to the whole section of wall (finishing included) was investigated (see Table 9).

In the first column of Table 9, the masonry type is reported; in the second column, the structural intervention applied to the wall combined with thermal plaster; the third column gives the new U-values; and in the fourth column another energy retrofitting intervention (EIFS) has been associated to the same structural intervention. The fifth column shows the thermal transmittance relative to the combined solution (seismic and energy retrofitting interventions) which has been calculated taking into account three feasible thicknesses of EIFS solution.

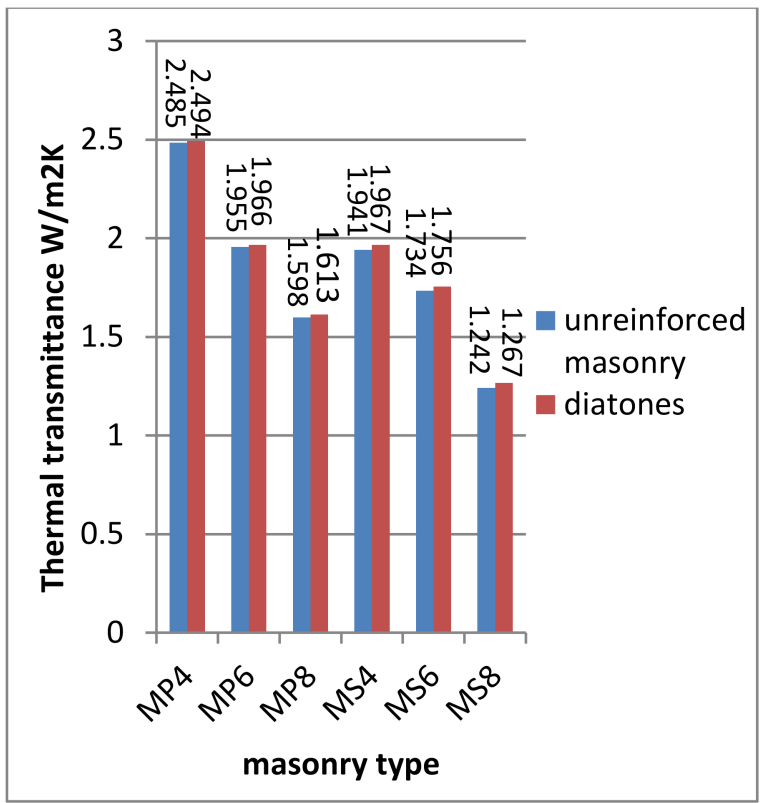

(a)

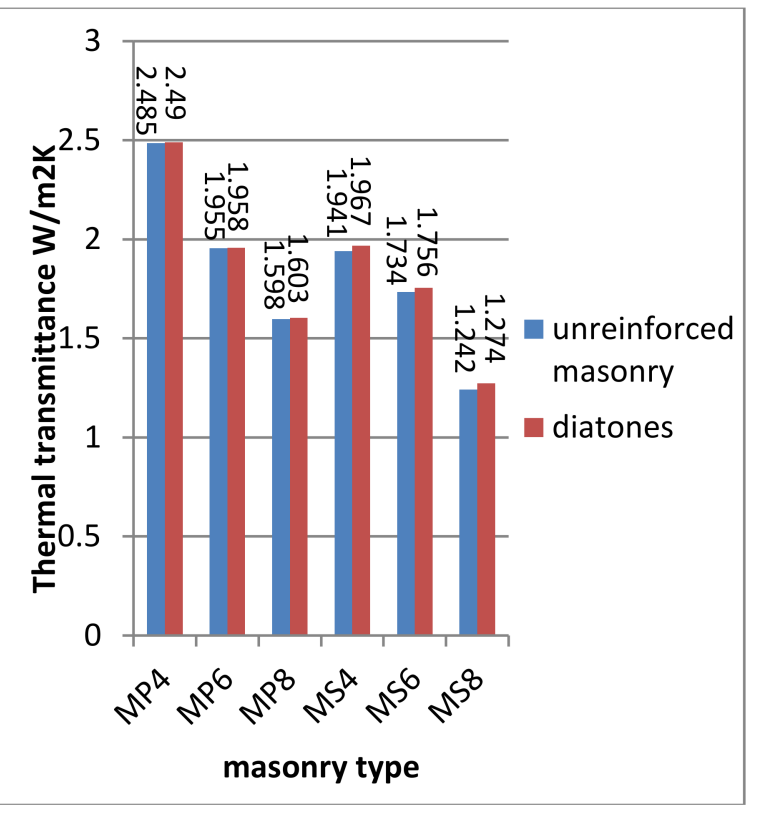

(b)

Figure 4. Effects of diàtonos interventions on U-value: (a) Diameter $=32 \mathrm{~mm}$; (b) Diameter $=100 \mathrm{~mm}$. 
Table 8. Effects on U-value of the structural interventions GI1, RP and GI + RP.

\begin{tabular}{|c|c|c|c|}
\hline ID & U-Value $\left(\mathrm{W} / \mathrm{m}^{2} \mathrm{~K}\right)$ Pre-Intervention & Intervention & U-Value $\left(\mathrm{W} / \mathrm{m}^{2} \mathrm{~K}\right)$ after Intervention \\
\hline MS4 & 2.485 & GI1 & 2.545 \\
\hline MS6 & 1.955 & GI1 & 2.006 \\
\hline MS8 & 1.598 & GI1 & 1.636 \\
\hline MR4 & 1.941 & GI1 & 2.081 \\
\hline MR6 & 1.734 & GI1 & 1.868 \\
\hline MR8 & 1.242 & GI1 & 1.353 \\
\hline MS4 & 2.485 & $\mathrm{GI} 1+\mathrm{RP}$ & 2.658 \\
\hline MS6 & 1.955 & $\mathrm{GI} 1+\mathrm{RP}$ & 2.077 \\
\hline MS8 & 1.598 & $\mathrm{GI} 1+\mathrm{RP}$ & 1.688 \\
\hline MR4 & 1.941 & $\mathrm{GI} 1+\mathrm{RP}$ & 2.160 \\
\hline MR6 & 1.734 & $\mathrm{GI} 1+\mathrm{RP}$ & 1.935 \\
\hline MR8 & 1.242 & $\mathrm{GI} 1+\mathrm{RP}$ & 1.391 \\
\hline MS4 & 2.485 & $\mathrm{RP}$ & 2.627 \\
\hline MS6 & 1.955 & $\mathrm{RP}$ & 2.043 \\
\hline MS8 & 1.598 & $\mathrm{RP}$ & 1.665 \\
\hline MR4 & 1.941 & $R P$ & 2.036 \\
\hline MR6 & 1.734 & $\mathrm{RP}$ & 1.808 \\
\hline MR8 & 1.242 & $\mathrm{RP}$ & 1.282 \\
\hline
\end{tabular}

Table 9. Effects on the energy efficiency interventions on the U-value.

\begin{tabular}{|c|c|c|c|c|c|c|}
\hline \multirow{2}{*}{ ID } & \multirow{2}{*}{ Intervention } & \multirow{2}{*}{ U-Value (W/m2K) } & \multirow{2}{*}{ Intervention } & \multicolumn{3}{|c|}{ U-Value (W/m2K) } \\
\hline & & & & $3 \mathrm{~cm}^{1}$ & $6 \mathrm{~cm}^{1}$ & $10 \mathrm{~cm}^{1}$ \\
\hline MS4 & GI1 + TP1 & 1.564 & GI1 + EIFS & 0.859 & 0.522 & 0.344 \\
\hline MS6 & $\mathrm{GI} 1+\mathrm{TP} 1$ & 1.342 & GI1 + EIFS & 0.788 & 0.495 & 0.332 \\
\hline MS8 & $\mathrm{GI} 1+\mathrm{TP} 1$ & 1.166 & $\mathrm{GI} 1+\mathrm{EIFS}$ & 0.723 & 0.469 & 0.320 \\
\hline MR4 & $\mathrm{GI} 1+\mathrm{TP} 1$ & 1.375 & GI1 + EIFS & 0.799 & 0.500 & 0.344 \\
\hline MR6 & $\mathrm{GI} 1+\mathrm{TP} 1$ & 1.279 & GI1 + EIFS & 0.765 & 0.486 & 0.328 \\
\hline MR8 & GI1 + TP1 & 1.014 & GI1 + EIFS & 0.662 & 0.442 & 0.308 \\
\hline MS4 & $\mathrm{GI} 1+\mathrm{RP}+\mathrm{TP} 1$ & 0.882 & $\mathrm{GI} 1+\mathrm{RP}+\mathrm{EIFS}$ & 0.859 & 0.523 & 0.344 \\
\hline MS6 & $\mathrm{GI} 1+\mathrm{RP}+\mathrm{TP} 1$ & 0.807 & GI1 + RP + EIFS & 0.788 & 0.495 & 0.332 \\
\hline MS8 & $\mathrm{GI} 1+\mathrm{RP}+\mathrm{TP} 1$ & 0.741 & GI1 + RP + EIFS & 0.725 & 0.469 & 0.320 \\
\hline MR4 & $\mathrm{GI} 1+\mathrm{RP}+\mathrm{TP} 1$ & 0.820 & $\mathrm{GI} 1+\mathrm{RP}+\mathrm{EIFS}$ & 0.800 & 0.500 & 0.334 \\
\hline MR6 & $\mathrm{GI} 1+\mathrm{RP}+\mathrm{TP} 1$ & 0.785 & GI1 + RP + EIFS & 0.767 & 0.487 & 0.328 \\
\hline MR8 & $\mathrm{GI} 1+\mathrm{RP}+\mathrm{TP} 1$ & 0.678 & GI1 + RP + EIFS & 0.664 & 0.443 & 0.308 \\
\hline MS4 & $\mathrm{RP}+\mathrm{TP} 1$ & 0.879 & RP + EIFS & 0.856 & 0.521 & 0.344 \\
\hline MS6 & $\mathrm{RP}+\mathrm{TP} 1$ & 0.802 & RP + EIFS & 0.783 & 0.493 & 0.331 \\
\hline MS8 & $\mathrm{RP}+\mathrm{TP} 1$ & 0.737 & RP + EIFS & 0.720 & 0.568 & 0.320 \\
\hline MR4 & $\mathrm{RP}+\mathrm{TP} 1$ & 0.801 & RP + EIFS & 0.782 & 0.493 & 0.331 \\
\hline MR6 & $\mathrm{RP}+\mathrm{TP} 1$ & 0.763 & RP + EIFS & 0.746 & 0.478 & 0.325 \\
\hline MR8 & $\mathrm{RP}+\mathrm{TP} 1$ & 0.651 & RP + EIFS & 0.638 & 0.432 & 0.302 \\
\hline
\end{tabular}

${ }^{1}$ The values refer to the thickness of EIFS.

It is worth noticing that not all the types of finishes analyzed in Table 3 and not all the energy efficiency solutions adopted in Table 9 are always compatible with the protection needs of historically important buildings. In Section 6, the aspects concerning the choice of better solutions will be discussed taking into account that restoration issues are a real restriction in case of high value finishes. The impact of the different finishes on the inner side, outside or on both faces of the wall for each intervention analyzed, was evaluated and is shown in Figures 5-7. 


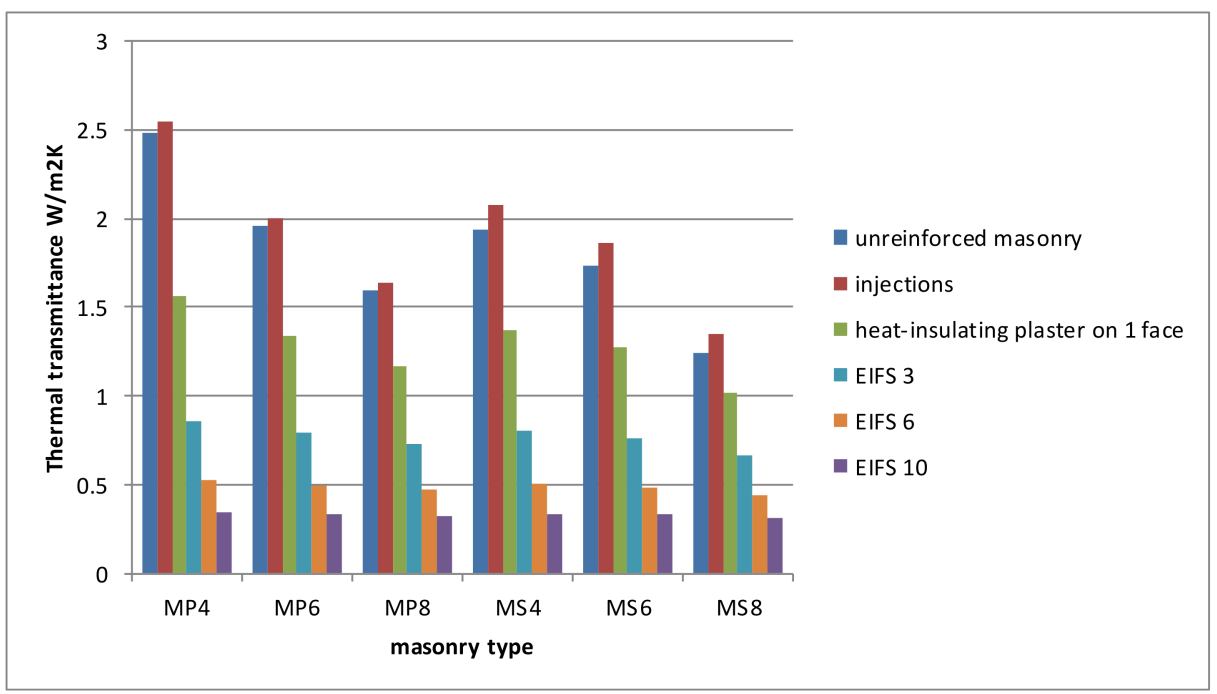

Figure 5. Comparison of the masonry thermal U-value before the interventions, after grout injections and after the application of finishing solutions for energy saving.

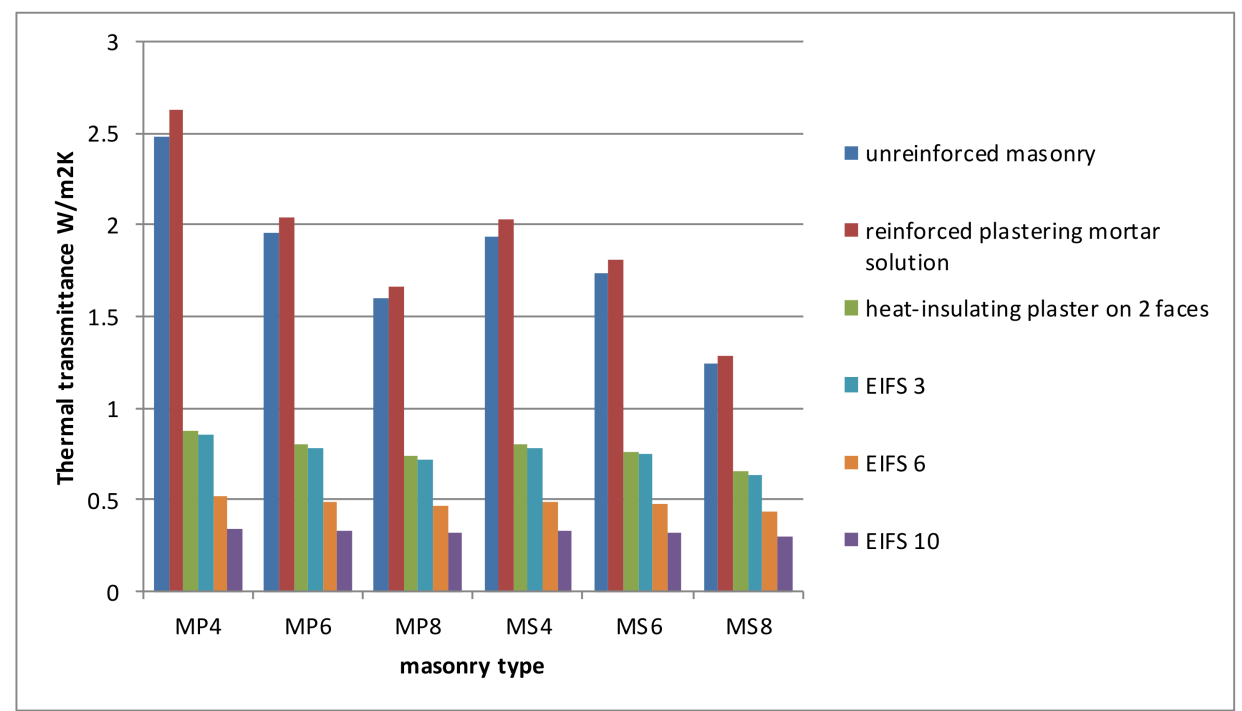

Figure 6. Comparison of the masonry thermal U-value before the interventions, after the steel mesh reinforced plastering mortar and after the application of finishing solutions for energy saving. 


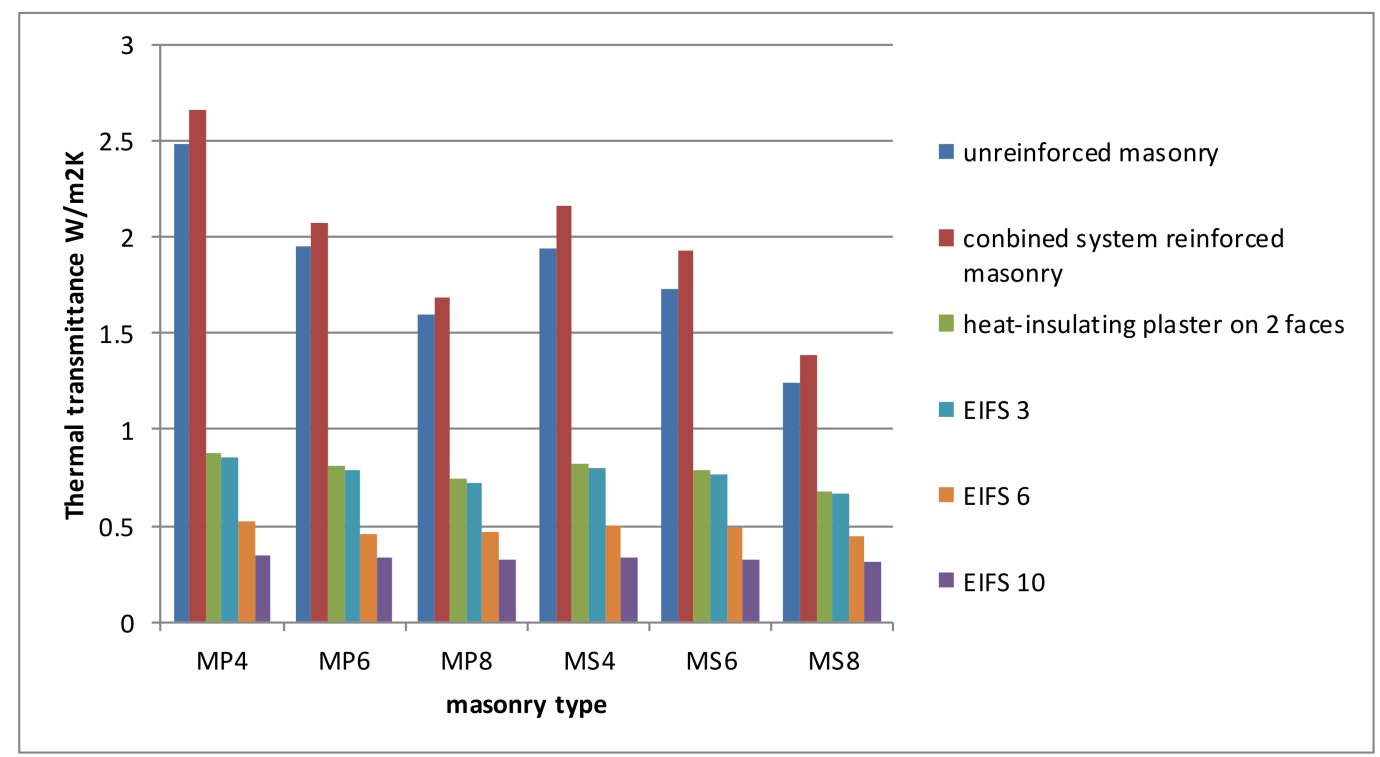

Figure 7. Comparison of the masonry thermal U-value before the interventions, after the combined reinforced system and after the application of finishing solutions for energy saving.

Finally, the intervention cost variations, caused by the use of more high performance materials in place of those used in current practice, were evaluated. These assessments were made using the regional list of Price Guidelines for Construction work in the Abruzzo Region "Prezzi Informativi Opere Edili della Regione Abruzzo". The prices indicated in this document are automatically applied in the execution of public works carried out in the Abruzzo region and, in particular, in the seismic retrofit interventions following the earthquake of 6 April 2009. The cost increment, due to the use of more high performance materials and to the different techniques adopted in the execution of finishes, was determined for each masonry analyzed, according to the following:

- Identification of all the techniques necessary for the execution of the structural improvement intervention; the cost of these techniques is constant and independent of the type of finishes adopted. The possibility of using structural materials with a higher energy performance in place of the traditional ones was not considered because it was not possible to find structural materials for which these performances were suitably certified in commerce. Lacking a reference performance standard, it is also difficult to justify the differences in cost of the materials themselves;

- Identification of the finishing techniques for the completion of the intervention, adopting finishing materials that do not possess particular energy performances;

- Application of high performance materials in place of standard materials. The possibility of adopting special plasters or EIFS of different thicknesses was considered. In Figures 8 and 9, the increment in cost relative to the use of more thermally performing materials is compared to the reduction of the U-value of the wall examined. The variation of the cost of the interventions only refers to the structural intervention. 


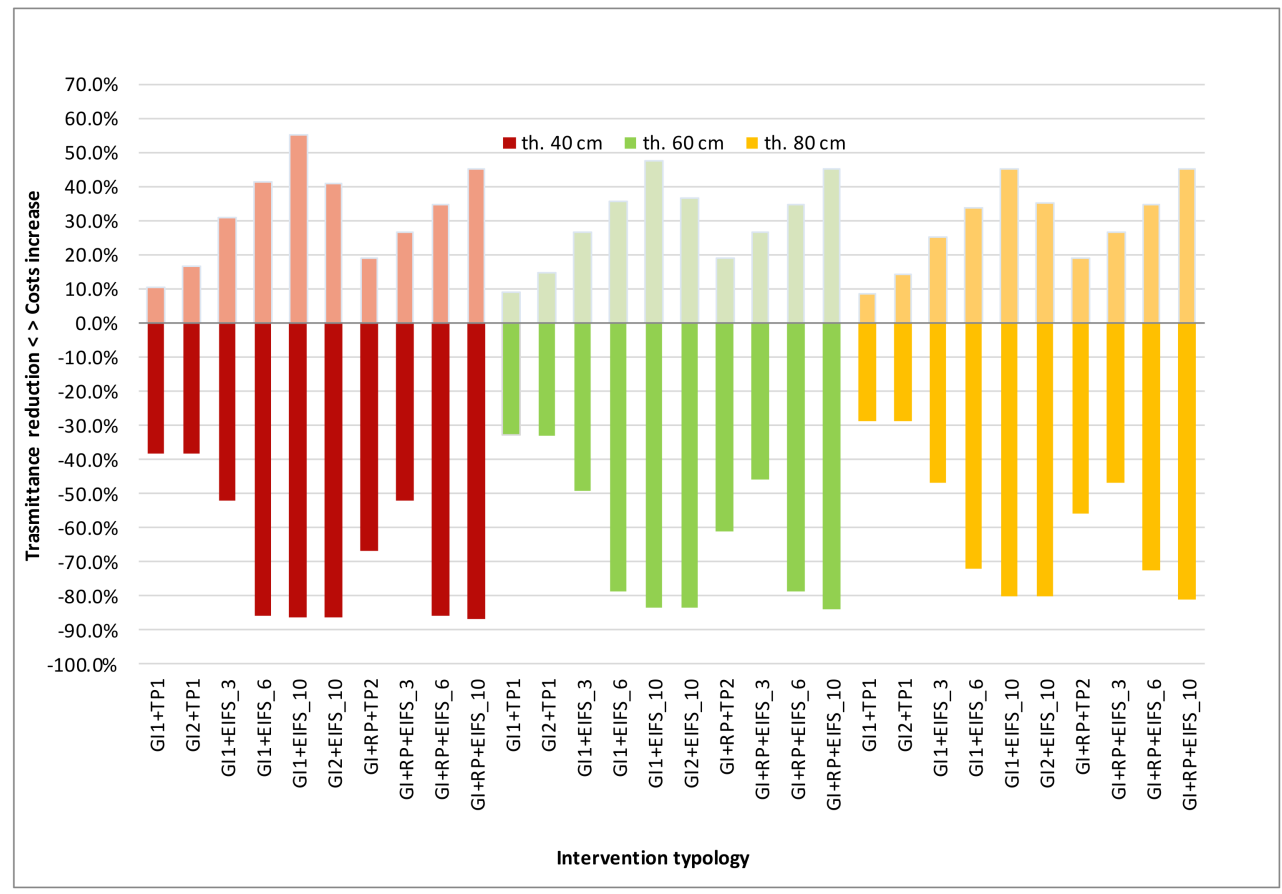

Figure 8. Transmittance reduction vs. costs increase for stone masonry.

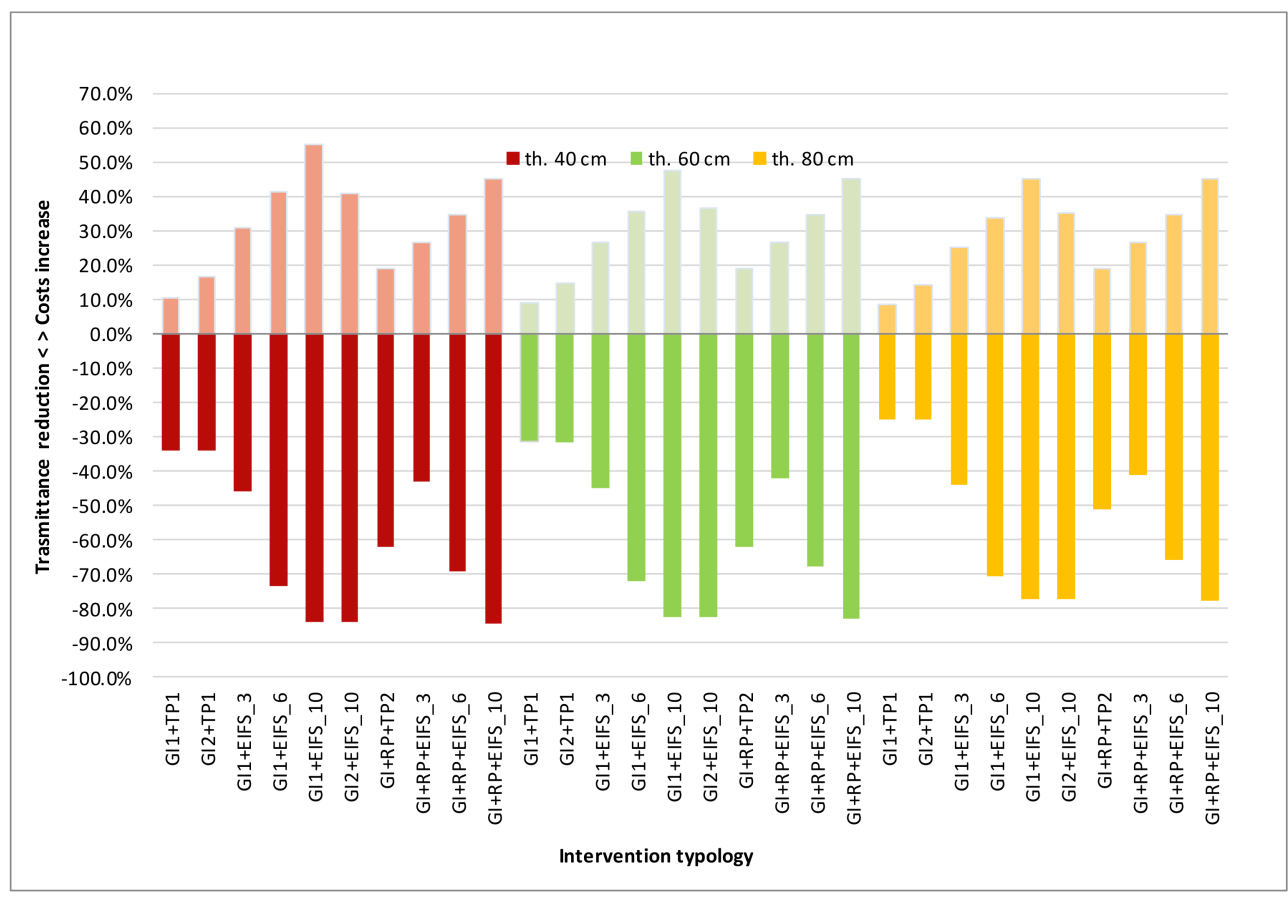

Figure 9. Transmittance reduction vs. costs increase for rubble masonry.

\section{Discussion}

In the previous analyses, the impact of structural interventions on masonry buildings was looked at from an energy efficiency perspective and in fact, the thermal characteristics of the structural materials analyzed are strictly connected to the building energy performance. This research demonstrates that these kinds of intervention can contribute to a worsening of the thermal performance of a wall, as Tables 8 and 9 highlight. The technological solutions suggested by this research are the 
adoption of thermal insulating plaster and exterior insulation finishing system (EIFS) to compensate this worsening: the use of thermal insulating plasters or EIFS on the reinforced masonry allows an improvement of the thermal characteristics of the opaque outer walls, considerably reducing the heat flow through the wall.

The analyses carried out also show that the use of diàtonoi in the masonry does not significantly worsen the thermal characteristics of the envelope: this means that energy saving can be achieved by optimizing heating and cooling systems rather than carrying out work specifically on the envelope. This evaluation is very useful in the case of historic buildings with valuable finishes that need to be conserved. On the contrary, the injection of grout and the reinforced plaster, applied separately or in a combined solution, have a significant impact on the thermal characteristics of the masonry, leading to an increase in terms of thermal transmittance, as shown in Table 8.

Table 9 shows the reduction of the U-value through the use of thermal insulating plaster ranges from $25 \%$ to $39 \%$ in the case of grout injection interventions, from $49 \%$ to $67 \%$ in the case of reinforced plaster and from $51 \%$ to $67 \%$ in the case of combined solutions (GI1 + RP). The use of EIFS solution can even reduce the U-value from $86 \%$ (10 cm thickness) to $50 \%$ ( $3 \mathrm{~cm}$ thickness). It is worth pointing out that the application of heat-insulating plaster delivers better results in masonry of less thickness, while the performances of EIFS only varies according to the thickness with which it is applied and almost independently of masonry type.

In the case of historically valuable buildings in which finishes often have to be preserved on one or on the two sides of the wall, the structural intervention has to be designed accordingly and the use of more extreme solutions such as EIFS are not always possible: the best architectural solution has to be arrived at by following a knowledge process that includes historical and non-destructive surveys to identify the valuable elements to be preserved [15]. The applicability and the compatibility of these more invasive interventions (GI1 + RP) must be verified case by case. It is evident that where an invasive structural intervention on the masonries that includes diffuse grout injections or even the removal of the historical plaster in favor of a mesh-reinforced plaster or FRP is adequate, other more advantageous solutions for the energy performance of the envelope are equally applicable.

The graphs in Figures 8 and 9 show the transmittance variations percentage and the relative costs increase, highlighting the variation of the combined intervention (structural and energy) with respect to the structural intervention alone. The examination of the diagrams shows the economical sustainability of combined interventions: for example thermal plaster application together with a structural injection and reinforced plaster, results in a reduction in the masonry U-value of $66 \%$, compared to a cost increase of less than $20 \%$. Similar results characterize other combined solutions such as the application of thermal insulating plaster and mortar injections ( $-32 \% \mathrm{U}$-value reductions, $10 \%$ costs increment) or a limited thickness of EIFS application $(-45 \%$ U-value, $+30 \%$ costs increment) in the case of rubble masonry.

In general, the execution of energy efficiency interventions, in conjunction with structural improvement interventions, results in economic savings linked to the reduction of demolitions and restoring of the finishing components. However, it should be noted that as the insulating capacity increases, the ratio between costs and benefits is reduced because the cost of raw materials gains an ever increasing weight in the overall burden of the intervention.

\section{Conclusions}

From the analyses carried out on the masonry typology considered, structural interventions inevitably result in an increment of the thermal conductivity of the wall. This increment is significant in those cases (that are often very frequent) which utilize grout injections or grout injections and reinforced plaster. However, it is negligible when using reinforcement techniques that include insertion of artificial diàtonoi for increasing the connection between multi-leaf masonry walls.

It was possible to constitute a catalogue of outer walls that have up-to-date thermal properties in function of the structural intervention and of the energy efficiency improvement associated with it. 
From the analyses, it is evident how an increment in U-values, due to the intervention of structural improvement, is drastically reduced by the use of technological solutions that are energy saving, such as EIFS or thermal insulating plaster. The use of structural materials with specific thermal properties that are currently little used would also reduce intervention costs.

Often solutions for finishes capable of compensating the increase of conductivity caused by the structural intervention or structural material with certified thermal characteristic are not frequently adopted because availability on the market is still limited. However, the use of lime, grout and mortar with low thermal conductivity could greatly reduce the thermal U-value of walls undergoing interventions to improve seismic vulnerability.

Acknowledgments: The authors would like to thank C.E.V. spa for providing the results of their grouting injection test employed in the analyses carried out in Section 4.2.

Author Contributions: Antonio Mannella conceived the research; Mariangela De Vita wrote the paper and performed the analyses on the masonries; Antonio Sabino and Antonio Mannella produced the graphics, analyzed the intervention cost variation and wrote Sections 6 and 7 with M.D.V.; Alessio Marchetti coordinated the research.

Conflicts of Interest: The authors declare no conflict of interest.

\section{References and Note}

1. Prez-Lombard, L.; Ortiz, J.; Pout, C. A review on buildings energy consumption information. Energy Build. 2008, 40, 394-398. [CrossRef]

2. Building Performance Institute Europe. Europe's Buildings under the Microscope; Building Performance Institute Europe (BPIE): Brussel, Belgium, 2011.

3. Buratti, C.; Belloni, E.; Palladino, D. Evolutive Housing system: Refurbishment with new technologies and unsteady simulations of energy performance. Energy Build. 2014, 74, 173-181. [CrossRef]

4. Buratti, C.; Belloni, E.; Lunghi, L.; Borri, A.; Castori, G.; Corradi, M. Mechanical characterization and thermal conductivity measurements using of a new 'small hot box' apparatus: Innovative insulating reinforced coatings analysis. J. Build. Eng. 2016, 7, 63-70. [CrossRef]

5. European Commission. Directive 2010/31/EU of the European Parliament and of the Council of 19 May 2010 on the Energy Performance of Buildings (Recast). Off. J. Eur. Union 2010, 18. Available online: https: / / eur-lex.europa.eu (accessed on 20 March 2018).

6. Legislative Decree 22 January, 2004 No. 42. Off. J. Ital. Repub. 2004, 28. Available online: http://www. gazzettaufficiale.it (accessed on 20 March 2018).

7. European Commission. Directive 2002/91/EC of the European Parliament and of the Council of 16 December 2002 on the Energy Performance of Buildings. Off. J. Eur. Communities 2002. Available online: https: / / eur-lex.europa.eu (accessed on 20 March 2018).

8. Italian Ministry of Economic Development. Ministerial Decree 26 June, 2015. Off. J. Ital. Repub. $2015,39$. Available online: http:/ / www.gazzettaufficiale.it (accessed on 20 March 2018).

9. Mazzarella, L. Energy retrofit of historic and existing building. The legislative and regulatory point of view. Energy Build. 2015, 95, 23-31. [CrossRef]

10. Vieites, E.; Vassileva, I.; Arias, J.E. European initiatives towards improving the energy efficiency in existing and historic buildings. Energy Procedia 2015, 75, 1679-1685. [CrossRef]

11. Kramer, R.P.; Maas, M.P.E.; Martens, M.H.J.; van Schijndel, A.W.M.; Schellen, H.L. Energy conservation in museums using different setpoint strategies: A case study for a state of the art museum using building simulations. Appl. Energy 2015, 158, 446-458. [CrossRef]

12. Zagorskas, J.; Zavadskas, E.K.; Turskis, Z.; Burinskiene, M.; Blumberga, A.; Blumberga, D. Thermal insulation alternatives of historic brick buildings in Baltic Sea Region. Energy Build. 2014, 78, 35-42. [CrossRef]

13. Ascione, F.; Ceroni, F.; De Masi, R.F.; de Rossi, F.; Pecce, M.R. Historical buildings: Multidisciplinary approach to structural/energy diagnosis and performance assessment. Appl. Energy 2017, 185, 1517-1528. [CrossRef]

14. Mannella, A.; De Vita, M.; Sabino, A. Interventi combinati di miglioramento sismico ed efficientamento energetico di edifici esistenti in muratura. In Proceedings of the 17th Anidis International Congress L'ingegneria sismica in Italia, Pistoia, Italy, 17-21 September 2017. 
15. De Berardins, P.; Bartolomucci, C.; Capannolo, L.; De Vita, M.; Laurini, E.; Marchionni, C. Instruments for Assessing Historical Built Environments in Emergency Contexts: Non-Destructive Techniques for Sustainable Recovery. Buildings 2018, 8, 27. [CrossRef]

16. Tiber, M.; Carbonara, E. Comparing energy improvements and financial costs of retrofitting interventions in a historical building. Energy Procedia 2016, 101, 995-1001. [CrossRef]

17. Calvi, G.M.; Sousa, L.; Ruggeri, C. Energy Efficiency and Seismic Resilience: A Common Approach. In Multi-Hazard Approaches to Civil Infrastructure Engineering; Gardoni, P., LaFave, J.M., Eds.; Springer International Publishing: Cham, Switzerland, 2016; pp. 165-208. [CrossRef]

18. Marques, R.; Lamego, P.; Lourenço, P.B.; Sousa, M.L. Efficiency and cost-benefit analysis of seismic strengthening techniques for old residential buildings in Lisbon. J. Earthq. Eng. 2018. [CrossRef]

19. Calvi, G.M. Choices and criteria for seismic strengthening. J. Earthq. Eng. 2013, 17, 769-802. [CrossRef]

20. Stazi, F.; Gregorini, B.; Gianangeli, A.; Bernardini, G.; Quagliarini, E. Design of a smart system for indoor climate control in historic underground built environment. Procedia Eng. 2017, 134, 518-527. [CrossRef]

21. Pisello, A.L.; Petrozzi, A.; Castaldo, V.L.; Cotana, F. On an innovative integrated technique for energy refurbishment of historical buildings: Thermal energy, economic and environmental analysis of a case study. Appl. Energy 2016, 162, 1313-1322. [CrossRef]

22. Italian Ministry of Cultural Heritage and Activities and Tourism. Guidelines for Energy Efficiency Improvements in the Cultural Heritage; MiBACT: Rome, Italy, 2015.

23. Mannella, A.; Martinelli, A. April 2009 Earthquake in Central Italy: Initial considerations about reconstruction costs and procedure. In Proceedings of the 19th International CIB World Building Congress, Brisbane, QSD, Australia, 5-9 May 2013.

24. Ludovico, M.D.; Prota, A.; Moroni, C.; Manfredi, G.; Dolce, M. Reconstruction process of damaged residential buildings outside historical centres after the L'AQUILA earthquake-Part 2: Heavy Damage, Reconstruction. Bull. Earthq. Eng. 2017, 15. [CrossRef]

25. Ludovico, M.D.; Prota, A.; Moroni, C.; Manfredi, G.; Dolce, M. Reconstruction process of damaged residential buildings outside historical centres after the L'Aquila earthquake-Part 1: Light Damage, Reconstruction. Bull. Earthq. Eng. 2017, 15, 667-693. [CrossRef]

26. Building Components and Building Elements_Thermal Resistance and Thermal Transmittance-Calculation Method; EN ISO 6946:2008; European Committee for Standardization: Brussels, Belgium, 2008.

27. Thermal Performance of Windows and Doors-Determination of Thermal Transmittance by the Hot-Box Method-Part 1: Complete Windows and Doors; EN ISO 12567-1:2010; European Committee for Standardization: Brussels, Belgium, 2010.

28. Building Materials and Products-Hygrothermal Properties-Procedure for Determining the Design Values, CTI-Thermal Insulation-Calculation and Test Methods (UNI/TS 11300-1); UNI 10351:2015; CTI (Italian Thermotechnical Committee): Milan, Italy, 2015.

29. Walls and Floors. Thermal Resistance Values and Calculation Method, CTI-Thermal Insulation-Calculation and Test Methods (UNI/TS 11300-1); UNI 10355:1994; CTI (Italian Thermotechnical Committee): Milan, Italy, 1994.

30. Vitruvius, P. De Architectura Libri Decem; Krohn, F., Ed.; B.G. Teubneri: Lipsiae, Germany, 1912; Volume 2, Chapter 8, Section 7; Available online: http:/ / www.perseus.tufts.edu/hopper/text?doc=Perseus\%3Atext\% 3A1999.02.0072\%3Abook\%3D2\%3Achapter\%3D8\%3Asection\%3D7 (accessed on 20 March 2018).

31. Italian Council of Ministers, Directive 9 February 2011 of the Council of Ministers. Off. J. Ital. Repub. $2011,47$.

32. Binda, L.; Modena, C.; Baronio, G.; Abbaneo, S. Repair and investigation techniques for stone masonry walls. Constr. Build. Mater. 1997, 11, 133-142. [CrossRef]

33. Artioli, G.; Casarin, F.; Benetta, M.D.; da Porto, F.; Secco, M.; Valluzzi, M.R. Restoration of historic masonry structures damaged by the 2009 Abruzzo earthquake through injection grouts. In Proceedings of the 9th Australasian Masonry Conference, Queenstown, New Zealand, 15-18 February 2011; pp. 15-18.

(C) 2018 by the authors. Licensee MDPI, Basel, Switzerland. This article is an open access article distributed under the terms and conditions of the Creative Commons Attribution (CC BY) license (http:/ / creativecommons.org/licenses/by/4.0/). 